\title{
Yoğun Bakım Ünitesinde Tedavi Gören Hastaların Algıladıkları Çevresel Stresörlerin Uyku Kalitesine Etkisi
}

\section{The Effect of Perception of Environmental Stressors on Sleep Quality of Patients Treated in Intensive Care Unit}

\author{
${ }^{1}$ Ayşegül GENCER, ${ }^{2}$ Azime KARAKOÇ KUMSAR \\ ${ }^{1}$ Bursa Çekirge Devlet Hastanesi, Bursa-Türkiye \\ ${ }^{2}$ Biruni Üniversitesi Sağlık Bilimleri Fakültesi Hemşirelik Bölümü, İstanbul-Türkiye \\ Ayșegül Gencer: https://orcid.org/0000-0003-3536-5520 \\ Azime Karakoç Kumsar: https://orcid.org/0000-0001-6178-2147
}

\section{ÖZ}

Amaç: Çalışma, yoğun bakım ünitesinde tedavi gören hastaların algıladıkları çevresel stresör düzeyinin uyku kalitesine etkisini değerlendirmek amacıyla gerçekleştirildi.

Materyal ve Metot: Tanımlayıcı, kesitsel ve ilişki arayıc1 tasarımda yapılan araştırmanın örneklemini, bir kamu hastanesinin ikinci basamak genel yoğun bakım ünitesinde yatan 270 hasta olușturdu. Araștırmanın verileri, "Hasta Onam Formu", "Hasta Tanıtım Formu", "Pittsburg Uyku Kalitesi Ölçeği (PUKİ)" ve "Yoğun Bakım Ünitesi Çevresel Stresörler Ölçeği (YBÜÇSÖ)" kullanılarak toplandı. Verilerin değerlendirilmesinde, studen t testi, Tek Yönlü ANOVA, Tukey HSD Post-hoc testi, Spearmen Korelasyon Analizi, Kruskal Wallis testi ve Mann Whitney U testi kullanild1.

Bulgular: Hastaların PUKİ ölçek toplam puan ortalamas1 $15,01 \pm 2,69$ ve YBÜÇSÖ toplam puan ortalaması $128,32 \pm 16,37$ olarak saptand. Hastaların çevresel stresör düzeyi ile öznel uyku kalitesi alt boyut toplam puanları arasında pozitif yönlü zayıf ilișki bulundu $(\mathrm{p}<0.05)$. Hastaların çevresel stresör düzeyi arttıkça uyku latansı alt boyut toplam puanları da artmakta (r:0,163); uyku süresi alt boyut toplam puanları azalmakta $(\mathrm{r}: 0,154)$ ve gündüz işlev bozukluğu süresi alt boyut toplam puanları artmakta (r:0,461) idi.

Sonuç: Hastaların uyku kalitesi kötü ve çevresel stresörlerden etkileme düzeyleri orta seviyededir. Hastaların çevresel stresör düzeyi arttıkça uyku kalitesi olumsuz yönde etkilenmektedir.

Anahtar Kelimeler: Çevresel stresörler, uyku kalitesi, yoğun bakım ünitesi

\begin{abstract}
Objective: The aim of this study was to evaluate the effect of perceived environmental stressors on sleep quality of patients treated in the intensive care unit.

Materials and Methods: The sampling of this descriptive, cross-sectional and relational design study was 270 patients who were hospitalized in a second line general intensive care unit of a public hospital. Data were collected using "Patient Consent Form", "Patient Identification Form", "Pittsburg Sleep Quality Scale (PSQI)" and "Intensive Care Unit Environmental Stressors Scale (ICUESS)". Independent Sample t test, One Way ANOVA, Tukey HSD Post-hoc test, Spearmen Correlation Analysis, Kruskal Wallis Test, Mann Whitney U test were used to evaluate the data.

Results: Mean PSQI total score of the participants was $15.01 \pm 2.69$, and sleep quality was poor. The mean total score ICUESS was $128.32 \pm 16.37$. A weak positive correlation was found between environmental stressor level and subjective sleep quality subscale total scores $(\mathrm{p}<0.05)$. As the environmental stressor level of the patients increased, sleep latency subscale total scores increased (r:0.163). As the environmental stressor level of the patients increased, total subscale scores of sleep duration decreased (r:0.154). As the environmental stressor level of the patients in creased, the subscale total scores of the duration of day time dysfunction also increased (r:0.461).

Conclusions: The sleep quality of the patients is poor and the level of influence from environmental stressors is moderate. As the environmental stressor level of the patients increases, sleep quality is negatively affected.

Keywords: Environmental stressor, intensive care unit, sleep quality
\end{abstract}

\author{
Sorumlu Yazar / Corresponding Author: \\ Azime Karakoç Kumsar \\ Dr. Öğr. Üyesi, Biruni Üniversitesi SABİF Hemşirelik Bölümü \\ Tel: 90 - 4448276 \\ Fax: 90 - 5336994603 \\ E-mail: azimekkoc@hotmail.com
}

\section{Yayın Bilgisi / Article Info:}

Gönderi Tarihi/ Received: 25/02/2020

Kabul Tarihi/ Accepted: 20/07/2020

Online Yayın Tarihi/ Published: 30/09/2020

Atıf / Cited: Gencer ve Karakoç Kumsar. Yoğun bakım ünitesinde tedavi gören hastaların algıladıkları çevresel stresörlerin uyku kalitesine etkisi. Online Türk Sağllk Bilimleri Dergisi 2020;5(3):434-443. doi: 10.26453/otjhs.694088 


\section{GİRIŞ}

Hastalık varlığı ve hastanede yatış süreci birçok birey için kaygı ve stres oluşturan ve tehdit edici bir faktör olarak kabul edilir. ${ }^{1}$ Bireyin algıladığ 1 stres düzeyi; hastalığın tanısı, bireyin buna yüklediği anlam, mevcut tanılama ve tedavi uygulamaları, önceki hastane deneyimleri, sosyo-kültürel seviyesi gibi birçok faktöre göre değişiklik gösterir. ${ }^{2}$

Yoğun bakım üniteleri (YBÜ), hayatı tehdit eden, akut ve kronik hastalık durumunda, hastaların yakın takip ve tedavilerinin yapıldığ 1 birimlerdir. İleri teknolojik özelliklere sahip yaşam destek cihazlarının kullanıldığı, hayati bulguların 24 saat takip edildiği, multidisipliner çalışan profesyonel sağlık personelinin bulunduğu, her türlü acil girişimin ve spesifik tedavinin yapıldığı, gerilim ve iş baskısının yoğun yaşandığ1 özellikli birimler olarak tanımlanmaktadır. ${ }^{3-6}$ Yoğun bakım ünitesinde gelişen teknolojiyle beraber çevresel stresörlere maruziyet de artmaktadır. Bu yönüyle YBÜ'nde tedavi gören hastalarının fiziksel ve psikososyal (refaketçi bulunmaması, ölüm korkusu, yalnızlık vb.) stresörlere maruz kaldığ ortamlar olarak da tanımlanması uygun olacaktir. ${ }^{7,8}$

Yoğun bakım ünitesinde stresörlerin değerlendirildiği çalışmalarda, uykusuzluk da kabul edilir önemli bir stresör olarak belirtilmektedir. ${ }^{2,4,7,9}$ Yoğun bakım hastalarında uyku yoksunluğu için en önemli hasta kaynaklı faktörler; altta yatan hastalığın türü ve ciddiyeti, akut hastalığın patofizyolojisi, gürültüye ve 1şığa uygun olmayan şekilde maruz kalma, mekanik ventilasyon, ağrı (prosedürlerden veya altta yatan durumdan), stres ve anksiyete olarak siralanmaktadır. ${ }^{10-12}$ Yoğun bakım ünitesine yatışı yapılan hastalarda da iyileşmenin sağlanması için kaliteli bir uyku önemli iyileştirici faktörlerden biri olarak kabul edilmektedir. Çünkü uykusuzluğun nitelik ve niceliksel durumu, immun sistem üzerinde fizyolojik ve psikolojik negatif geri bildirimlere neden olabilmektedir. $^{13}$

Çevre, uykuya geçişi kolaylaştıracağı gibi olumsuz yönde de etkileyebilmektedir. Yoğun bakım hemşiresinin uyku kalitesini olumsuz etkileyen stresörlerin farkında olması ve oluşabilecek sonuçları bilmesi, kritik hastaların uykularının düzenlenmesi ve gerekli olan iyileştirici hemşirelik uygulamaları için büyük önem taşımaktadır. ${ }^{7,14,15}$

$\mathrm{Bu}$ bağlamda bu çalışma, YBÜ'nde tedavi gören hastaların algıladıkları çevresel stresör düzeyinin uyku kalitelerine etkisini değerlendirmek amaciyla yapıld1.

\section{MATERYAL VE METOT}

Araştırmanın Tipi ve Amacı: Araştırma, YBÜ'nde tedavi gören hastaların algıladıkları çevresel stresör düzeyinin uyku kalitesine etkisini değerlendirmek amacıyla; tanımlayıcı, kesitsel ve ilişki arayıcı tasarımda gerçekleştirildi.

Araştırmanın Etik Yönü: Verileri toplamadan önce, bir üniversitenin etik kurulundan etik onay (karar no: 2018/ 13-36) ve araştırmanın yürütüldüğü hastaneden yazılı kurum izni alındı. Araştırmada veri toplama aşamasında gönüllülük, özerklik/bireye sayg1, mahremiyet ve eşitlik ilkeleri göz önüne al1narak hastalara araştırmanın amacı sözlü ve yazılı olarak onam formuyla aktarild.

Araştırmanın Yeri ve Zamanı: Araştırma Bursa ilinde, bir devlet hastanesinin ikinci basamak genel yoğun bakım ünitesinde 02 Nisan 2018 - 28 Şubat 2019 tarihleri arasında yürütüldü.

Araştırmanın Evreni ve Örneklemi: Araştırmanın evrenini, çalışmanın yürütüldüğü hastanenin geçmiş bir yılında ikinci basamak genel yoğun bakım ünitesine yatan 953 hasta oluşturdu. Buna göre; örneklem hesabı ile minimum 274 hastanın çalışmaya dahil edilmesi uygun bulundu. Çalışmamızda, hedeflenen örneklem sayısına ulaşıldı, ancak istatiksel analizde nomal dağılım elde edebilmek için uç değerlerin çalışma dışı bırakılması sonucunda cevapların tutarsızlık olduğu değerlendirilen dört hasta çalışma dışı bırakıldı. Böylece, YBÜ'sinde en az 24 saat en fazla 72 saattir (72 saatten sonra deliryum gelişeceğinden bu süreyi aşan hastalar araştırmaya alınmadı) tedavi gören, iletişime ve iş birliğine açık olan, Türkçe bilen, 18 yaşından büyük, şiddetli ağrısı olmayan, soruları tam ve eksiksiz cevaplayan, araştırmaya gönüllü olarak katılmayı kabul eden toplam 270 hasta örneklemi oluşturdu.

Veri Toplama Araçları: Veriler, Hasta Tanıtım Formu", " Pittsburg Uyku Kalitesi Ölçeği (PUKİ)" ve "Yoğun Bakım Ünitesi Çevresel Stresörler Ölçeği (YBÜÇSÖ)" kullanılarak elde edildi.

Hasta Tanıtım Formu; araştırmacılar tarafindan literatür incelenerek hazırlanan bu formda; sosyodemografik özellikler ile yatış süresi, yatış tanısı, yoğun bakım ünitesine yatışı, uyku alışkanlığı, yoğun bakım ünitesinin uyku düzenine etkisi gibi hastanın hastanede yatışına ilişkin özelliklerini içeren toplam 15 soru bulunmaktadır. ${ }^{16,17}$

Pittsburg Uyku Kalitesi Ölçeği (PUKI); uyku kalitesinin belirlenmesi amaciyla kullanılan PUKİ, 1989 senesinde Buysse ve arkadaşları aracılığıyla gelişti- 
rilmiş, ölçeğin Türkçe geçerlik güvenirlik çalışması Ağargün ve ark. ${ }^{18}$ tarafından yapılmış ve cronbach alfa katsayısı 0,80 olarak saptanmıştır. Çalışmada, ölçeğin cronbach alfa değeri 0,81 olarak saptandi. Toplam 24 soru içeren ölçeğin; "öznel uyku kalitesi”, "uyku latansı”, "uyku süresi”, "alışılmış uyku etkinliği”, "uyku bozukluğu”, "uyku ilacı kullanımı", "gündüz işlev bozukluğu" olmak üzere yedi bileşeni bulunmaktadır. Ölçekten minimum 0, maksimum 21 puan alınmaktadır. Toplam ölçek puanın 5 ve üzerinde olması yüksek olması uyku kalitesinin kötü olduğunu göstermektedir. Ölçek puanı uyku bozukluğu olup olmadığı ya da uyku bozuklarının yaygınlığını göstermemektedir. ${ }^{17,18}$

Yoğun Bakım Ünitesi Çevresel Stresörler Ölçeği (YBÜÇSÖ); 1981 y1lında Ballard tarafindan geliştirilmiş, 1989 yılında Cochran and Ganong tarafindan tekrar revize edilmiştir. Ölçeğin ülkemizde geçerlik güvenirlik çalışması, 2010 yılında Aslan ve Çınar tarafından ${ }^{19}$ yapılmış ve ölçeğin cronbach alfa katsayısı 0,94 olarak bulunmuştur. Çalışmada ise, cronbach alfa katsayısı 0,89 olarak saptandı. Ölçek, toplam 42 maddeden oluşmakta ve derecelendirme 4'lü likert şeklinde yapılmaktadır. Likert değerlendirmesi, "Hiç etkilemez" (1), "Çok az etkiler" (2), "Sıklıkla etkiler" (3), "Çok fazla etkiler" (4) şeklindedir ve her madde için verilen puan esas alınmaktadır. Ölçeğin tamamı için en düşük puanı 42, en yüksek puanı 168'dir. Ölçek puanı arttıkça çevresel stresörlerden etkilenme oranının arttığını gösterir. Ölçeğin kesme değeri bulunmamaktadır.

Uygulama: Yazılı ve sözel onamları alındıktan sonra araştırma kriterlerine uyan ve araştırmaya katılmayı kabul eden hastalardan formları yüz yüze görüşme yöntemi ile cevaplamaları istendi. Her bir hasta ile görüşme ortalama $20 \mathrm{dk}$ sürdü. Tüm sorular1 tam olarak tamamlayan katılımcılar araştırma kapsamına alınd.

Verilerin Değerlendirilmesi: Çalışmada elde edilen verilerin istatistiksel analizleri için IBM SPSS Statistics 22 (IBM SPSS, Türkiye) programı kullanıldı. Hastaların sosyo-demografik özellikleri, PUKİ ve YBÜÇSÖ puanlarının tanımlanmasında; frekans, yüzde, aritmetik ortalama standart sapma ve minimum-maksimum değerler kullanıldı. Bağımsız değişkenler ile PUKİ ve YBÜÇSÖ puan ortalamaları ile arasındaki ilişki varyans analizleri ile değerlendirildi. Parametrik test varsayımları sağlandığı durumlarda bağımsız örneklem t testi ve tek yönlü ANOVA kullanıldı. Farklılığa neden olan grubun tespitinde ise Tukey HSD post-hoc testi kullanıldı. Parametrik test varsayımları sağlanmadığı durumlarda ise non-parametrik testlerden Kruskal Wallis analizi kullanıldı. Tek yönlü varyans analizinde farklılığa neden olan grubun belirlenmesinde Tukey testi, Kruskal Wallis analizinde farklılığa neden olan grubu tespit etmek için Mann Whitney U testi kullanıld1. YBÜÇSÖ ile PUKİ alt boyut puan ortalamaları arasındaki ilişkinin değerlendirilmesinde spearman korelasyon analizi kullanıldı. Sonuçlar \%95 güven aralığında, $\mathrm{p}<0,05$ anlamlılık düzeyinde değerlendirildi.

Araştırmanın Sınırlılıkları: Araştırma bulguları, tek bir yoğun bakım ünitesi hastalarından elde edilen veriler ve kullanılan PUKİ ve YBÜÇSÖ ölçeklerin ölçtüğü değerlerle sınırlıdır.

\section{BULGULAR}

Araştırma; \%39,3'ü (n:106) kadın ve \%60,7'si (n:164) erkek olmak üzere toplam 270 hasta ile yapıldı. Hastaların yaş ortalaması $57,43 \pm 14,76$ idi. Araştırmaya katılan hastaların, \%43,7'sini (n:118) solunum sistemi hastalıkları ile ilgili yatış tanısı alan hastaların oluşturduğu belirlendi. Hastaların \%38,5'i (n:104) daha önceden de YBÜ'ne yatarak tedavi gördüğünü belirtti. Hastaların \%74,4'ünün (n:201) YBÜ'ne yatış tanısı dışında hekim tarafından tanı konulmuş en az bir kronik hastalığı olduğu saptandı. Hastaların toplam YBÜÇSÖ puan ortalaması $128,32 \pm 16,37$ iken, genel PUKI puan ortalaması ise, $15,01 \pm 2,59$ 'dur. Hastaların PUKİ alt boyut puanları incelendiğinde; en yüksek alt boyut puanı gündüz işlev bozukluğu puanı iken, en düşük PUKİ alt boyut puanı ise öznel uyku kalitesi alt boyut puanıdır (Tablo 1).

Hastaların uyku sorunu yaşama nedenleri incelendiğinde; hastalarda görülen en sik uykusuzluk nedeninin uyku saatlerinde yapılan tıbbi ve hemşirelik müdahaleleri \%58,9 (n:159) ve ağrı düzeyinin yüksek olmas1 \%54,8 (n:148) olarak saptandı (Tablo 2).

Çalışmada, katılımcıların toplam YBÜÇSÖ puan ortalamaları ile PUKİ toplam puan ortalamaları arasında pozitif yönlü zayıf ilişki tespit edildi. Bu duruma göre; hastaların YBÜÇSÖ puanları arttıkça PUKİ toplam puanları da artmaktadır (r:0,154), ( $\underline{\text { Tablo }}$ 3).

Hastaların toplam YBÜÇSÖ puanları ile "öznel uyku kalitesi” ve "uyku latansı" alt boyut toplam puanları arasında pozitif yönlü zayıf ilişki ve "gündüz işlev bozukluğu" alt boyut toplam puanları arasında orta kuvvetli ilişki tespit edildi. Bu duruma göre; hastaların YBÜÇSÖ puanları arttıkça "öznel uyku kalitesi" ve "uyku latansı" ve "gündüz işlev bozukluğu" alt boyut toplam puanları da artmaktadır 
(sırasıyla r:0,181; r:0,163; r:0,461). Hastaların toplam YBÜÇSÖ puanları ile "uyku süresi" alt boyut toplam puanları arasında ise, negatif yönlü zayıf ilişki tespit edildi. Bu bulguya gore, hastaların YBÜÇSÖ puanları arttıkça "uyku süresi” alt boyut toplam puanları azalmaktadır (r:-0,154). Hastaların toplam YBÜÇSÖ puanları ile "alışılmış uyku etkinliği”, "uyku bozukluğu" ve "uyku ilacı kullanma" alt boyut toplam puanları arasında bir ilişki saptanmadı (sirasiyla r:0,040; r:0,105; r:0,059), (Tablo 3).

Hastaların en fazla algıladıkları stresörler incelendiğinde; "mahremiyetin olmaması" faktörünün diğer faktörlere oranla yüksek olduğu bulundu (Tablo 4).

\section{TARTIŞMA VE SONUÇ}

Çalışmada, katılımcıların YBÜÇSÖ toplam puanları 74 ile 164 arasında değişmekte olup; ölçek toplam puan ortalamas1 128,32 $\pm 16,37$ bulundu. Bu bulguya göre, YBÜ'nde tedavi gören hastaların çevresel stresörlerden etkilenme düzeyinin orta düzeyde olduğu söylenebilir. Yapılan benzer çalışmalar incelendiğinde; ölçek toplam puan ortalamasının $80.65 \pm 18.46$ ve $120,88 \pm 20,7$ arasında değişkenlik gösterdiği görülmektedir. ${ }^{7,9,19-21}$ Çalışma bulgumuz, benzer sonuçlar göstermekle birlikte farklılıklar da göstermektedir. $\mathrm{Bu}$ farklılıkların sosyo-demografik özellikler, yaş, cinsiyet, öz yeterlilik düzeyi, hastalığın şiddeti, yatışının yapıldığ1 YBÜ ortamı, yatış tanısı gibi birden fazla nedenden kaynaklandığı düşünülmektedir.

Çalışmada, PUKİ genel puan ortalaması 15,01 $\pm 2,69$ olarak saptandı. Bu bulgu, yoğun bakım hastalarının uyku kalitesinin kötü olduğunu göstermektedir. Uğurlu ve Sabuncu (2012) çalışmasında, ${ }^{17}$ YBÜ hastalarının PUKİ puan ortalaması 7,48 $\pm 4,97$, Erim ve Çamdeviren (2018) çalışmasında, ${ }^{22} 10,98 \pm 4,34$ olarak saptanmıştır. Çalışma bulgumuz, benzer çalışma bulgularına göre, çalışmayı yürüttüğümüz yoğun bakım hastalarında uyku kalitesinin daha kötü düzeyde olduğunu göstermektedir. Yurt dişında yürütülen çalışma sonuçları da, yoğun bakım hastalarında uyku kalitesinin kötü düzeyde olduğuna dikkat çekmektedir. ${ }^{10,23}$ Yapılan benzer çalışma bulgularının, çalışma bulgumuz ile benzer sonuçlar göstererek yoğun bakım hastalarında uyku kalitesinin bozulduğu görülmektedir. Kaliteli bir uyku, hastalar için önemli iyileştirici faktörlerden biri olarak kabul edilmekte, uykusuzluğun immun sistem üzerinde fizyolojik ve psikolojik negatif geri bildirimlere neden olduğu bildirilmektedir. ${ }^{13}$ Kritik hastaların izlendiği YBÜ'nde daha kaliteli ve uzun süreli uyku için bireysel girişimlerin planlanması, yeni stratejiler geliştirilmesi, bu anlamda hastaların iyileşme süreç- lerine de olumlu yönde katkı sağlayacaktır.

Çalışmada, hastalar uyku sorunu yaşama nedenleri olarak ilk sırada uyku saatlerinde yapılan tıbbi/ hemşirelik müdahaleleri ve ağrı yaşama durumlarını gösterdi. Hastalıkla ilgili endişe, ortamın soğukluğu, ortamdaki hasta sayısının fazla olması, yabancı ortam, 1şık ve gürültü de sırasıyla en sık şikayet edilen uykusuzluk nedenleri olarak sıralanmaktadır.

Yoğun bakım ünitesinde uykuyu etkileyen birçok faktör olduğu bilinmektedir. ${ }^{24}$ Uğurlu ve Sabuncu (2012) çalışmasında, ${ }^{17}$ uyku sorunu yaşama nedenleri gürültü $(\% 25,8)$, 1şık $(\% 21,7)$, ortamın soğukluğu $(\% 21,7)$, hastalıkla ilgili endişeler $(\% 19,2)$, yabancı ortam $(\% 19,2)$, uyku saatlerinde yapılan tıbbi ve hemşirelik müdahaleleri $(\% 16,7)$, ortamdaki hasta sayısının fazla olması $(\% 7,5)$ olarak belirlenmiştir. Benzer bir çalışmada da, YBÜ hastalarının uyku sorunu yaşama nedenleri olarak gürültü, ağrı, hastalıkla ilgili kaygıları, tek kişilik odada kendini yalnız hissetme, uyku saatindeki tıbbi müdahaleler ve gece 1şı̆̆ın açık kalması olarak belirlenmiştir. ${ }^{22}$ Little et al. çalışmasında da, ${ }^{25}$ uyku sorunu yaşama nedenleri gürültü (\%43), ağrı (\%40), pozisyon bozukluğu (\% $35)$, yüksek sesle konuşma (\%33), takılan kateterler (\%33) ve zaman oryantasyon bozukluğu (\%29) olarak saptamıştır. Çalışmamız, benzer çalışma bulgular1 ile paralellik göstermekte; sıralamalar arasında farklılık gözlense de en sık uykusuzluk nedeni olarak sıklıkla gürültü, ağrı, yapılan girişimsel müdahaleler ve hastalıkla ilgili endişelerin gösterildiği gözlenmektedir.

Uyku vaktinde uygulanan hemşirelik bakım faaliyetlerinin, uykuyu önemli düzeyde kesintiye uğrattığı vurgulanmaktadır. $^{15,24,26,27}$ Uyku bölünmelerinin olması ve hastaların tekrar uykuya dalmalarında zorluk yaşamalarının, uyku problemine sebep olduğu unutulmayarak; uyku saatlerinde yapılan tıbbi ve hemşirelik müdahalelerin acil ve temel bakım ihtiyaçlar dışında mümkün olduğunca gündüz saatlerine planlanması daha kaliteli bir uyku sürecine katkı sağlayacaktır.

Hastaların uyku kalitesi kötü düzeylerde olmakla birlikte, çevresel stresörlerden etkilenme düzeyleri orta seviyededir. Hastaların çevresel stresör düzeyi arttıkça uyku kalitesi olumsuz yönde etkilenmektedir. Yoğun bakım hemşirelerinin, hastaların çevreye uyumunu sağlamaları ve uyku kalitesi düzeylerini arttırması yönünden destekleyici girişimleri uygulaması önerilmektedir. Uykunun değerlendirilmesi, alışkanlıkların tespit edilmesi ve uykuyu etkileyen bireysel ve çevresel etkenlerin düzenlenmesi, yoğun bakım ekibine hastaların uyku kaliteleri ve uyku ile 
ilgili sorunlarına ilişkin farkındalıklarını arttırma yönünde etkili olacaktır.

Etik Komite Onayı: Biruni Üniversitesi Girişimsel Olmayan Araştırmalar Etik Kurulu'ndan 2018/ 1336 karar no ile çalışmanın etik kurul onayı alınmıştir.

Çıkar Çatışması: Yazarlar çıkar çatışması bildirmemişlerdir.

Yazar Katkıları: Fikir - AKK, AG; Tasarım - AKK; Veri toplanması ve/veya işlemesi - AG; Analiz ve/ veya yorum - AG, AKK; Literatür taraması - AG; Yazıyı yazan - AG, AKK; Eleştirel inceleme AKK.

Hakem değerlendirmesi: D1ş bağımsız.

\section{KAYNAKLAR}

1. Fredriksen SD, Ringsberg KC. Living the situation stress-experiences among intensive care patients. Intensive and Critical Care Nursing. 2007;23:124-131.

2. Tunçay GY, Uçar H. Hastaların yoğun bakım ünitesinin fiziksel ortam özelliklerine ilişkin görüşleri. Hacettepe Üniversitesi Sağlık Bilimleri Fakültesi Hemşirelik Dergisi. 2010;33-46.

3. Uysal N, Gündoğdu N, Börekçi S, Dikensoy Ö, Uyar M. Üçüncü basamak merkezde dahili yoğun bakım hastalarının prognozu. Yoğun Bakım Dergisi. 2010;1(1):1-5.

4. Hweidi IM. Jordanian patients' perception of stressors in critical care units: a questionnaire survey. International Journal of Nursing Studies. 2007;44(2):227-235.

5. Rotondi A, Chelluri L, Sirio C. Patients' recollections of stressful experiences while receiving prolonged mechanical ventilation in an intensive care unit. Crit Care Med. 2002;30(4):746-752.

6. Aslan F. Yoğun bakım ünitesinde tedavi gören hastaların algıladıkları çevresel stresörler: geçerlilik ve güvenirlilik çalışması. Danışman: Yrd. Doç. Dr. Sezgi ÇINAR. Marmara Üniversitesi, Sağlık Bilimleri Enstitüsü. Yüksek Lisana Tezi, İstanbul, 2010.

7. Aktaş Y, Karabulut N, Yılmaz D, Özkan S. Kalp damar cerrahisi yoğun bakım ünitesinde tedavi gören hastaların algıladıkları çevresel stresörler. Kafkas J Med Sci. 2015;5(3):81-86.

8. Dedeli Ö, Akyol DA. Yoğun bakım hastalarında psikososyal sorunlar. Yoğun Bakım Hemşireliği Dergisi. 2008;12(1-2):26-32.
9. So HM, Chan DSK. Perception of stressors by patients and nurses of critical care units in Hong Kong. International Journal Of Nursing Studies. 2004;41(1):77-84.

10. Elliott R, McKinley S, Cistulli P, Fien M. Characterisation of sleep in intensive care using 24hour polysomnography: An observational study. Crit Care. 2013;17:R46.

11.Bihari S, Doug McEvoy R, Matheson E, Kim S, Woodman RJ, Bersten AD. Factors affecting sleep quality of patients in intensive care unit. J Clin Sleep Med. 2012;8:301-307.

12. Biren BK, 15Dale MN, Nancy AC. Sleep deprivation in critical illness: It is role in physical and psychological recovery. J Instensive Care Med. 2010;27(2):97-111.

13. Friese RS. Sleep and recovery from critical illness and injury: A review of theory current practice and future directions. Crit Care Med. 2008;36:697-705.

14. Velioğlu P. Hemşirelikte Kavram Ve Kuramlar. Akademi Basın ve Yayıncılık, İstanbul. 2012. s. 184-212.

15. Karagözoğlu Ş, Çabuk S, Tahta Y, Temel F. Hastanede yatan yetişkin hastaların uykusunu etkileyen bazı faktörler. Toraks Dergisi. 2007;8(4):234 -240 .

16. Gökçe S. Kalp yetmezliği olan hastaların uyku kalitesinin ve etkileyen etmenlerin incelenmesi. Danışman: Yrd. Doç. Dr. Hatice Mert. Dokuz Eylül Üniversitesi, Sağlık Bilimleri Enstitüsü. Yüksek Lisans Tezi, İzmir, 2008.

17. Uğurlu T. Yoğun bakım ünitesinde yatan ve serviste takip edilen hastaların uyku kalitesi ve sorunlarının değerlendirilmesi. Danışman: Prof. Dr. Necmiye Sabuncu. Haliç Üniversitesi, Sağlık Bilimleri Enstitüsü. Yüksek Lisans Tezi, İstanbul, 2012.

18. Ağargün MY, Kara H, Anlar Ö. Pittsburg Uyku Kalitesi İndeksi' nin Geçerlilik ve Güvenirliliği. Türk Psikiyatri Dergisi. 1996;7(2):107-115.

19.Zaybak A, Çevik K. Yoğun bakım ünitesindeki stresörlerin hasta ve hemşireler tarafindan alg1lanmas1. Yoğun Bakim Dergisi. 2015;6(1):4-9.

20. Yava A, Tosun N, Ünver V, Çiçek H. Patient and nurse perceptions of stressors in the intensive care unit. Stress and Health. 2011;27(2):36-47.

21. Hewitt J. Psycho-affective disorder in intensive care units: A review. Journal of Clinical Nursing. 2002;11(5):575-584. 
22. Erim H. Yoğun bakım ünitesinde yatan hastaların uyku kalitesinin belirlenmesi. Danışman: Dr. Öğr. Üyesi Esra Köroğlu Çamdeviren. Medipol Üniversitesi, Sağlık Bilimleri Enstitüsü. Yüksek Lisans Tezi, İstanbul, 2018.

23. Sareli AE, Schwab RJ. The sleep-friendly ICU. Crit Care Clin. 2008;24(3):613-626.

24. Pisani MA, Friese RS, Gehlbach BK, Schwab RJ, Weinhouse GL. Sleep in the instensive care unit. Am J Respir Crit Care Med. 2015;191 (7):731-738.

25. Little A, Ethier C, Ayas N, Thanachayanont T, Jiang D, Mehta S. A patient survey of sleep quality in the intensive care unit. Minerva Anestesiol. 2012;78:406-414.

26. Çelik S, Öztekin D, Akyolcu N, Işsever H. Sleep disturbance: The patient care activities applied at the night shift in the intensive care unit. J Clin Nurs. 2005;14(1):102-106.

27. Tamburri LM, DiBrienza R, Zozula R, Redeker NS. Nocturnal care interactions with patients in critical care units. Am J Crit Care. 2004;13 (2):102-112. 
Tablo 1. YBÜÇSÖ ve PUKİ toplam puan ve alt boyut puan ortalamalarının dağılımı (N=270).

\begin{tabular}{|l|c|c|c|c|}
\hline Ölçekler & Minimum & Maximum & $\overline{\mathbf{x}}$ & SS \\
\hline YBÜÇSÖ Toplam Puan & 74,00 & 164,00 & 128,32 & 16,37 \\
\hline PUKİ Toplam Puan & 8,00 & 21,00 & 15,01 & 2,69 \\
\hline Öznel Uyku Kalitesi &, 00 & 3,00 &, 40 &, 89 \\
\hline Uyku Latansı &, 00 & 3,00 & 1,62 &, 74 \\
\hline Uyku Süresi & 1,00 & 3,00 & 1,72 & 2,02 \\
\hline Alışılmış Uyku Etkinliği &, 00 & 3,00 &, 80 & 1,14 \\
\hline Uyku Bozukluğu &, 00 & 3,00 & 1,59 &, 65 \\
\hline Uyku İlacı &, 00 & 3,00 & 1,06 & 1,02 \\
\hline Gündüz İşlev Bozukluğu & 1,00 & 3,00 & 2,63 &, 49 \\
\hline
\end{tabular}


Tablo 2. Hastaların uyku sorunu yaşama nedenlerinin dağılımları $(\mathrm{N}=270)$.

\begin{tabular}{|l|c|c|}
\hline Uyku Sorunu Yaşama Nedenleri & $\mathbf{n}$ & $\mathbf{\%}$ \\
\hline Ağrı & 148 & 54,8 \\
\hline Gürültü & 65 & 24,1 \\
\hline Hastalıkla İlgili Endişe & 118 & 43,7 \\
\hline Işık & 79 & 29,3 \\
\hline Ortamın Sıcaklığı & 3 & 1,1 \\
\hline Ortamın Soğukluğu & 116 & 43,0 \\
\hline Uyku Saatlerinde Yapılan Tıbbi ve Hemşirelik Müdahaleleri & 159 & 58,9 \\
\hline Ortamdaki Hasta Sayısının Fazla Olması & 95 & 35,2 \\
\hline Yabancı Ortam & 84 & 31,1 \\
\hline
\end{tabular}


Tablo 3. Hastaların toplam YBÜÇSÖ puanı ile PUKİ toplam ve alt boyut puanları arasındaki ilişkinin değerlendirilmesi ( $\mathrm{N}=270)$.

\begin{tabular}{|c|c|c|c|c|c|c|c|c|c|}
\hline & & 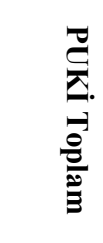 & 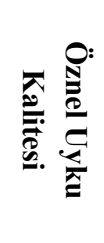 & 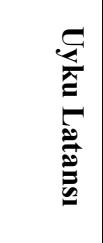 & 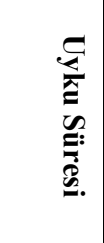 & 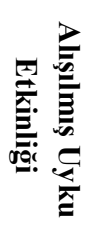 & 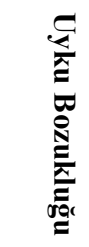 & 珶 & 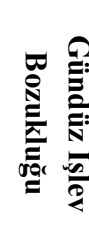 \\
\hline \multirow[t]{2}{*}{ YBÜÇSÖ } & $\mathbf{r}^{*}$ & 0,154 & 0,181 & 0,163 & 0,154 & 0,040 & 0,105 & 0,059 & 0,461 \\
\hline & $\mathbf{p}$ & 0,011 & 0,003 & 0,007 & 0,018 & 0,513 & 0,085 & 0,335 & 0,000 \\
\hline
\end{tabular}

* Spearman korelasyon analizi yapılmıştır. 
Tablo 4. En fazla stresör olarak algılanan faktörler $(\mathrm{N}=270)$.

\begin{tabular}{|l|c|}
\hline En fazla stresör olarak algılanan faktörler & Ortalama \pm SS \\
\hline Mahremiyetin olmaması & $3.82 \pm 0.46$ \\
\hline Diğer hastaların ağlama/inlemelerini duymak & $3.74 \pm 0.55$ \\
\hline Erkek ve kadınların aynı odada kalmaları & $3.71 \pm 0.64$ \\
\hline Sikılmak & $3.70 \pm 0.59$ \\
\hline Saatin/ zamanın ne olduğunu bilmemek & $3.59 \pm 0.73$ \\
\hline Işıkların sürekli açık olması & $3.58 \pm 0.67$ \\
\hline A ğrı olması & $3.57 \pm 0.66$ \\
\hline Burnunuzda veya ağzınızda tüplerin olması & $3.55 \pm 0.66$ \\
\hline Serum setleri nedeniyle ellerinizi ve kollarınızı hareket ettirememeniz & $3.55 \pm 0.72$ \\
\hline Çevredeki alışık olmadık kokuları duymak & $3.54 \pm 0.67$ \\
\hline
\end{tabular}

